\title{
CONVECÇÃO LINEARMENTE ORGANIZADA NA ÁREA DE PETROLINA, SEMI-ÁRIDO DO NORDESTE DO BRASIL: ASPECTOS EM MESO E GRANDE ESCALA
}

\author{
FABRÍCIO DANIEL DOS SANTOS SILVA ${ }^{1}$, MAGALY DE FÁTIMA CORREIA ${ }^{2}$ \\ MARIA REGINA DA SILVA ARAGÃO ${ }^{2}$, JONATAN MOTA DA SILVA ${ }^{3}$ \\ ${ }^{1}$ Instituto Nacional de Meteorologia \\ ${ }^{2}$ Universidade Federal de Campina Grande \\ ${ }^{3}$ Universidade de São Paulo \\ fabricio.silva@inmet.gov.br, \\ magaly@dca.ufcg.edu.br, \\ regina@dca.ufcg.edu.br, \\ jsilva@model.iag.usp.br
}

Recebido Maio 2007 - Aceito Maio 2008

\begin{abstract}
RESUMO
É apresentado um estudo sobre sistemas convectivos linearmente organizados e observados por um radar meteorológico banda-C na região semi-árida do Nordeste do Brasil. São analisados três dias (27 a 29) de março de 1985, com ênfase na investigação do papel desempenhado por fatores locais e de grande escala no desenvolvimento dos sistemas. No cenário de grande escala, a área de cobertura do radar foi influenciada por um cavado de ar superior austral no dia 27 e por um vórtice ciclônico de altos níveis no dia 29. A convergência de umidade próxima à superfície favoreceu a atividade convectiva nos dias 27 e 29, enquanto que divergência de umidade próxima à superfície inibiu a atividade convectiva no dia 28 . No cenário de mesoescala, foi observado que o aquecimento diurno é um fator importante para a formação de células convectivas, somando-se a ele o papel determinante da orografia na localização dos ecos. De maneira geral, as imagens de radar mostram os sistemas convectivos linearmente organizados em áreas elevadas e núcleos convectivos intensos envolvidos por uma área de precipitação estratiforme. Os resultados indicam que convergência do fluxo de umidade em grande escala e aquecimento radiativo, são fatores determinantes na evolução e desenvolvimento dos ecos na área de estudo.
\end{abstract}

Palavras-chave: sistema convectivo de mesoescala, linha de instabilidade, vórtice ciclônico de altos níveis, radar meteorológico banda-C

\begin{abstract}
LINEARLY-ORGANIZED CONVECTION IN THE PETROLINA AREA, SEMIARID OF NORTHEASTERN BRAZIL: LARGE AND MESOSCALE ASPECTS

A study on linearly organized convective systems observed by a C-band meteorological radar in the semi-arid area of Northeast Brazil is presented. The convective activity during three selected days of 1985 March (27 to 29) was analyzed emphasizing the role played by local and large-scale factors on the development of rain systems. On the large-scale scenario, the covered radar area was influenced by an austral upper-level air trough on March 27th and by an upper-level cyclonic vortex on the 29th. Near-surface moisture convergence favored convective activity on days 27 and 29 , while near-surface moisture divergence inhibited convective activity on day 28 . On the mesoscale, it was found that diurnal heating was an important factor influencing the formation of the convective cells, while their location was determined mainly by the orography. In general, the radar images show the linearly-organized convective systems over elevated terrain and intense convective cells embedded by a stratiform rain area. The results indicate that large-scale convergence of the moisture flux and radiative heating are determinant factors on the evolution and development of the echoes in the area of study.
\end{abstract}

Keywords: mesoscale convective system, squall line, upper-level cyclonic vortex, C-band meteorological radar 


\section{INTRODUÇÃO}

A precipitação na Região Nordeste do Brasil apresenta grande variabilidade espacial e temporal causada pela atuação de fenômenos atmosféricos de várias escalas. O semi-árido apresenta máximas precipitações durante março e abril. Além da grande variabilidade sazonal, ocorrem também grandes flutuações interanuais no semi-árido, que provocam fenômenos extremos como as secas severas ou enchentes. Anos atípicos como 1985, que apresentou chuvas acima da média em todo o Nordeste, são de grande interesse na busca de uma melhor compreensão dos fatores determinantes das condições de tempo e clima na região. Os eventos de chuva estão associados a mecanismos dinâmicos de grande escala, entre os quais: Zona de Convergência Intertropical-ZCIT (Hastenrath, 1984; Moura e Shukla, 1981), penetração de sistemas oriundos de latitudes médias austrais (Kousky, 1979), Vórtices Ciclônicos de Altos Níveis - VCAN (Kousky e Gan, 1981) e a Oscilação de Madden-Julian (Kousky e Kayano, 1994). A ocorrência desses fenômenos favorece a formação de sistemas de mesoescala profundos, que provocam chuvas intensas, a exemplo dos aglomerados convectivos e linhas de instabilidade. As linhas de instabilidade recebem essa denominação por serem sistemas constituídos de células convectivas profundas linearmente organizadas. Elas ocorrem em áreas tropicais e extratropicais, continentais e oceânicas.

Muitos trabalhos tratam das características dos sistemas de grande escala, que provocam chuva no semi-árido do Nordeste do Brasil podendo-se citar Hastenrath e Heller (1977), Kousky (1979), Kousky e Gan (1981), Kousky e Kayano (1994), entre outros. Por outro lado, são poucos os trabalhos que enfocam os sistemas de mesoescala que atuam na região (Silva Aragão et al., 2007; Barbosa e Correia, 2005; Diniz et al., 2004). Neste estudo, imagens de um radar meteorológico banda-C, obtidas durante a estação chuvosa de 1985 na região de Petrolina-PE $\left(9^{\circ} 24^{\prime} \mathrm{S}, 40^{\circ} 29^{\prime} \mathrm{W}, 377 \mathrm{~m}\right)$, permitem avaliar a distribuição e organização dos ecos, e analisar sua formação, desenvolvimento e intensificação num círculo de $250 \mathrm{~km}$ de raio, e assim detectar sistemas organizados com características de linhas de instabilidade, a exemplo das linhas de instabilidade da região amazônica (Garstang et al., 1994; Greco et al., 1994; Cohen et al., 1995).

Assim, este trabalho tem como objetivo identificar e analisar sistemas convectivos linearmente organizados formados no semi-árido nordestino em março de 1985, por meio de produtos do radar meteorológico operado em Petrolina, e investigar o papel desempenhado por fatores locais e de grande escala no desenvolvimento desses sistemas. Além de contribuir para ampliar o conhecimento sobre os mesmos, os resultados obtidos também podem auxiliar na validação de experimentos numéricos de alta resolução para a região.

\section{MATERIAL E MÉTODOS}

Inicialmente, foi analisado todo o mês de março de 1985 considerando que estudos já realizados (Silva Aragão et al., 2000; Araújo, 1996) mostram que este foi o mês com a maior freqüência de ocorrência de ecos linearmente organizados e identificados em campos de precipitação obtidos pelo radar meteorológico banda-C de Petrolina-PE, operado pelo Instituto de Atividades Espaciais do Centro Tecnológico Aeroespacial (IAE-CTA, atualmente o Instituto de Aeronáutica e Espaço do Centro Técnico Aeroespacial). Foram selecionados três dias: 27,28 e 29 , sendo que o dia 28 se diferencia dos demais por não apresentar ecos com organização linear.

O radar instalado em Petrolina-PE $\left(9^{\circ} 24^{\prime} \mathrm{S}, 40^{\circ} 29^{\prime} \mathrm{W}\right.$, $372 \mathrm{~m}$ ), no vale do Rio São Francisco, cobria uma área circular de $400 \mathrm{~km}$ de raio (Figura 1). Um círculo interior a este, de 250 $\mathrm{km}$ de raio, representa a área em que os ecos foram analisados. As características do radar meteorológico de Petrolina podem ser encontradas em Correia (1989).

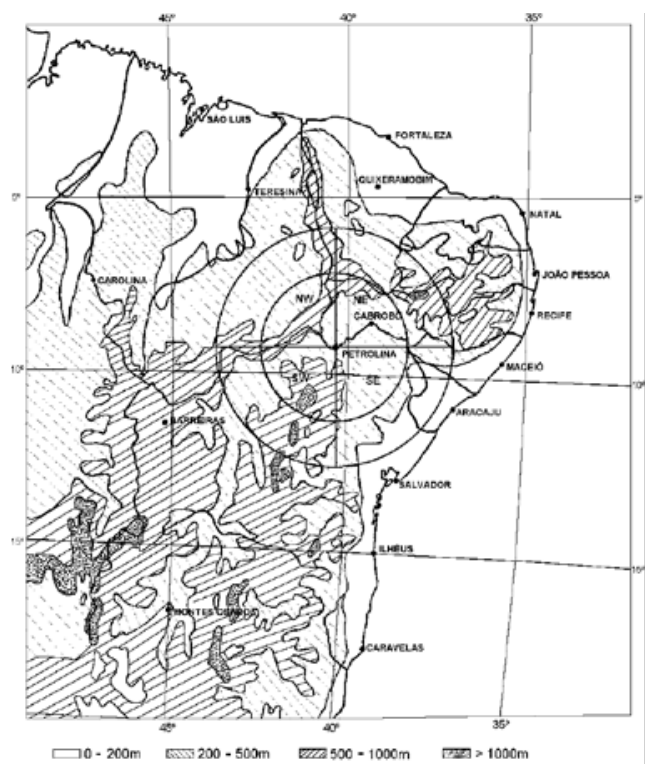

Figura 1 - Relevo do Nordeste do Brasil e área circular coberta pelo radar meteorológico banda-C de Petrolina-PE $\left(9^{\circ} 24^{\prime} \mathrm{S}, 40^{\circ} 30^{\prime} \mathrm{W}\right)$ representada pelo círculo maior com raio de $400 \mathrm{~km}$. O círculo menor (raio de $250 \mathrm{~km}$ ) é a área na qual foi feito o registro dos ecos. A convenção utilizada para o relevo é vista no rodapé do mapa. (Fonte: Silva Aragão et al., 2000).

Os dados do radar possibilitaram diagnosticar a estrutura de mesoescala de sistemas de chuva que atuaram na região nos dias considerados. Os ecos linearmente organizados, linhas de ecos (LE) e faixas de ecos (FE), analisados neste trabalho (Figura 2) obedecem aos critérios de dimensão e organização dos ecos utilizados por Silva Aragão et al. (2000) para identificar padrões de ecos (Tabela 1) em imagens de radar na forma de seções horizontais (PPI) e seções verticais (RHI). 


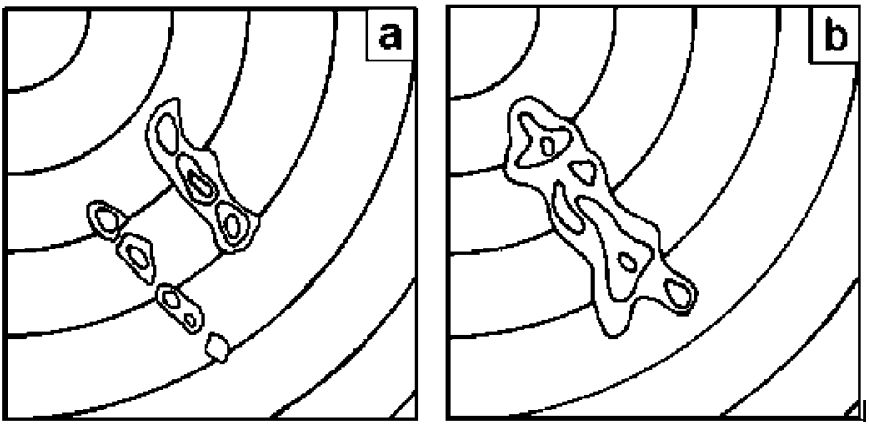

Figura 2 - Representação idealizada dos padrões de ecos de radar observados na região de Petrolina durante a estação chuvosa de 1985: (a) linhas de ecos (LE) e (b) faixa de ecos (FE). Os ecos aparecem no quadrante sudeste da área de cobertura do radar apenas para ilustração. A distância entre cada circunferência corresponde a $50 \mathrm{~km}$. O contorno externo de refletividade representa o

Tabela 1 - Características Básicas dos Padrões de Ecos Analisados (Fonte: Adaptado de Silva Aragão et al., 2000).

\begin{tabular}{ccccc}
\hline \multirow{2}{*}{$\begin{array}{c}\text { PADRÖFS } \\
\text { DL LCOS }\end{array}$} & \multicolumn{3}{c}{ CARACTFRÍSTICAS } \\
\cline { 2 - 4 } & $\begin{array}{c}\text { LXILNSAO } \\
(\mathrm{km})\end{array}$ & $\begin{array}{c}\text { LARGURA } \\
\text { MAXIMA } \\
(\mathrm{km})\end{array}$ & IORMA & DLSCRIÇÃO \\
\hline $\begin{array}{c}\text { linha de ecos } \\
\text { (Figura 2a) }\end{array}$ & $50 \leq \mathrm{L} \leq 100$ & 17 & linear & $\begin{array}{c}\text { - ecos isolados alinhados on } \\
\text { núcleos intentios alinhthados } \\
\text { dentro de una célula } \\
\text { individual. }\end{array}$ \\
\hline $\begin{array}{c}\text { faixa de ecos } \\
\text { (Figura 2b) }\end{array}$ & $70 \leq \mathrm{F} \leq 150$ & 30 & linear & - uma célula \\
\hline
\end{tabular}

Estudos observacionais evidenciam que as propriedades dinâmicas de sistemas convectivos profundos (convecção isolada ou organizada em mesoescala) dependem de fatores como instabilidade termodinâmica e cisalhamento vertical do vento. Amplas evidências indicam que o desenvolvimento desses sistemas tem forte relação com a Energia Potencial Disponível para Convecção (CAPE) e é influenciado pelo cisalhamento vertical do vento na baixa troposfera (Domingues et al., 2004).

ACAPE é uma medida da energia de flutuação que indica o grau de instabilidade termodinâmica da atmosfera. Segundo Zawadzki e Ro (1978) é dada por:

$$
\mathrm{CAPE}=\mathrm{g} \int_{\mathrm{NCL}}^{\mathrm{NE}}\left(\frac{\theta_{(\mathrm{Z})}-\bar{\theta}_{(\mathrm{Z})}}{\bar{\theta}_{(\mathrm{z})}}\right) \mathrm{d} \mathrm{Z}
$$

Nessa equação $g$ é a aceleração da gravidade, é a temperatura potencial de uma parcela de ar que sobe adiabaticamente saturada a partir do nível de condensação por levantamento (NCL) até o nível de equilíbrio (NE), $\theta_{(\mathrm{z})}$ é a temperatura potencial virtual do ambiente.

Foram calculados tambémos valores da Energia Convectiva de Inibição(CINE) para os mesmos dias. Esse parâmetroédado por:
CINE $=g \int_{Z_{0}}^{\mathrm{NCL}}\left(\frac{\theta_{(\mathrm{Z})}-\bar{\theta}_{(\mathrm{z})}}{\bar{\theta}_{(\mathrm{Z})}}\right) \mathrm{dZ}$

Dados de superfície e de sondagens de ar superior coletados na sede do radar foram analisados a fim de investigar a estabilidade da atmosfera por meio dos perfis verticais das temperaturas potencial $(\theta)$, potencial equivalente $(\theta \mathrm{e})$ e potencial equivalente de saturação ( $\theta \mathrm{es})$, calculadas de acordo com Bolton (1980). Valores da CAPE de uma parcela de ar da superfície, obtidos a partir do valor mais alto da temperatura potencial do bulbo úmido determinado com base nos dados de superfície coletados nos horários sinóticos na sede do radar, representam a Energia Máxima da Parcela à Superfície (Emáx). Na sua obtenção foi utilizada a metodologia desenvolvida por Zawadzki e Ro (1978) e modificada por Correia (1989), sendo denominada de energia potencial convectiva disponível máxima ( $\left.\mathrm{CAPE}_{\mathrm{MAX}}\right)$. A necessidade de obter o máximo valor da CAPE, através da substituição dos dados do primeiro nível das sondagens, foi motivada pelos horários de lançamento das sondas, próximos das $12 \mathrm{HL}$, quando a atividade convectiva máxima observada na região ocorre no período da tarde.

A presença de instabilidade condicional/convectiva é essencial para a formação de células convectivas. No entanto, a instabilidade termodinâmica não é o único fator que influencia o comportamento de uma tempestade. As tempestades mais severas em termos de produção de ventanias e granizo ocorrem em condições de forte cisalhamento vertical do vento (Silva Dias, 1987). O cisalhamento vertical do vento foi investigado através de perfis verticais das componentes zonal (u) e meridional $(\mathrm{v})$.

$\mathrm{Na}$ análise do ambiente de grande escala, dados de reanálises dos National Centers for Environmental Prediction/ National Center for Atmospheric Research (NCEP/NCAR) em pontos de grade nos níveis isobáricos padrões (umidade específica, componentes zonal e meridional do vento, movimento vertical), para os horários das 12:00 e 18:00 UTC, foram utilizados. Esses dados possibilitaram diagnosticar a circulação em escala sinótica e investigar o papel desempenhado pela divergência horizontal do fluxo de umidade no desenvolvimento dos ecos. Imagens do satélite meteorológico METEOSAT obtidas na banda do infravermelho térmico às 11:55 UTC, também foram utilizadas, com o intuito de ajudar na avaliação do grau de atividade convectiva sobre o Nordeste durante o período estudado.

\section{RESULTADOS E DISCUSSÕES}

Durante o período de estudo, as condições atmosféricas na área de Petrolina passaram por importantes mudanças 
provocadas pela interação entre sistemas de circulação atmosférica dos dois hemisférios. Características em escala sinótica e em mesoescala são discutidas a seguir.

\subsection{Características em Escala Sinótica}

\subsubsection{Análise das imagens de satélite}

As imagens de satélite, disponíveis para o período da manhã, são aqui usadas para fornecer uma visão geral da atividade convectiva sobre o Nordeste nos dias selecionados.
Na imagem de satélite do dia 27 (Figura 3a) são vistos núcleos convectivos profundos e organizados em áreas do Nordeste, embora a área de cobertura do radar não apresente nebulosidade. A imagem do dia 28 (Figura 3b) evidencia que houve um considerável aumento da área coberta por nuvens no Nordeste. A imagem do dia 29 (Figura 3c) mostra com clareza a área de nebulosidade em forma de arco associada a um vórtice ciclônico de altos níveis (VCAN) formado sobre o Nordeste. A análise da evolução de episódios convectivos específicos (LEs e FEs), ocorridos no período da tarde, é feita no item 3.2.
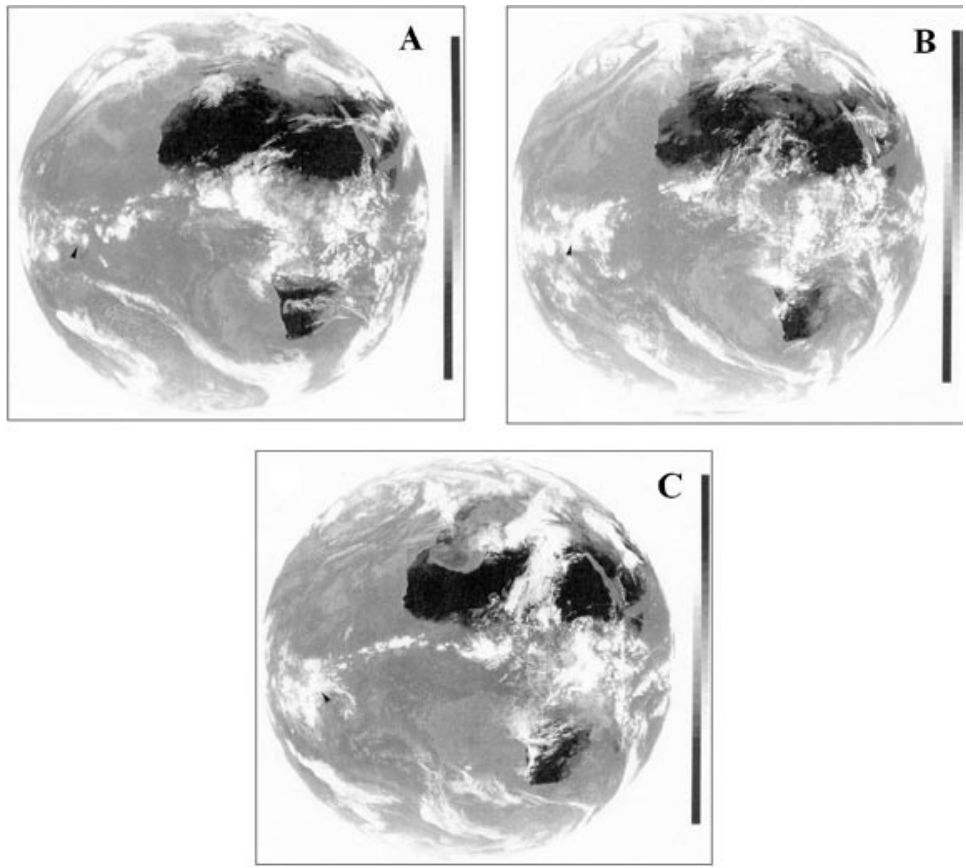

Figura 3 - Imagens no canal do infravermelho térmico do satélite METEOSAT para as 11:55 UTC do dia: (a) 27, (b) 28 e (c) 29 de março de 1985. A ponta da flecha no lado esquerdo das imagens coincide com a localização (aproximada) de Petrolina. (Fonte das imagens: European Space Agency).

\subsubsection{Análise dos campos em altos e baixos níveis}

$\mathrm{Na}$ Figura 4 é ilustrado o escoamento no nível de $250 \mathrm{hPa}$, para as 12:00 UTC dos três dias selecionados. A escolha desse horário para análise se deu pela coincidência com o horário das imagens de satélite, o que facilita a comparação entre essas informações. No dia 27 (Figura 4a), a região da América do Sul é influenciada por dois centros de divergência em altos níveis: o anticiclone da Bolívia, com centro ao sul de sua posição climatológica, e o anticiclone centrado ao norte do continente, em torno de $10^{\circ} \mathrm{N}$. Também é evidente o cavado sobre a área tropical do Atlântico Norte, com eixo em torno de $35^{\circ} \mathrm{W}$, cuja extremidade equatorial está próxima de $5^{\circ} \mathrm{N}$. No dia 28 (Figura 4b), pode-se observar a amplificação desse cavado e a permanência de sua extremidade equatorial sobre o Attântico Norte. No dia 29 (Figura 4c), há uma circulação ciclônica fechada sobre o Nordeste caracterizando uma situação de VCAN intenso, pois foi observado que este se estendia até o nível de $500 \mathrm{hPa}$ (não mostrado). Aparentemente, a formação desse sistema não segue rigorosamente o modelo conceitual proposto por Kousky e Gan (1981), já que não é evidente a amplificação do cavado à jusante do anticiclone da Bolívia precedendo a formação do VCAN. 

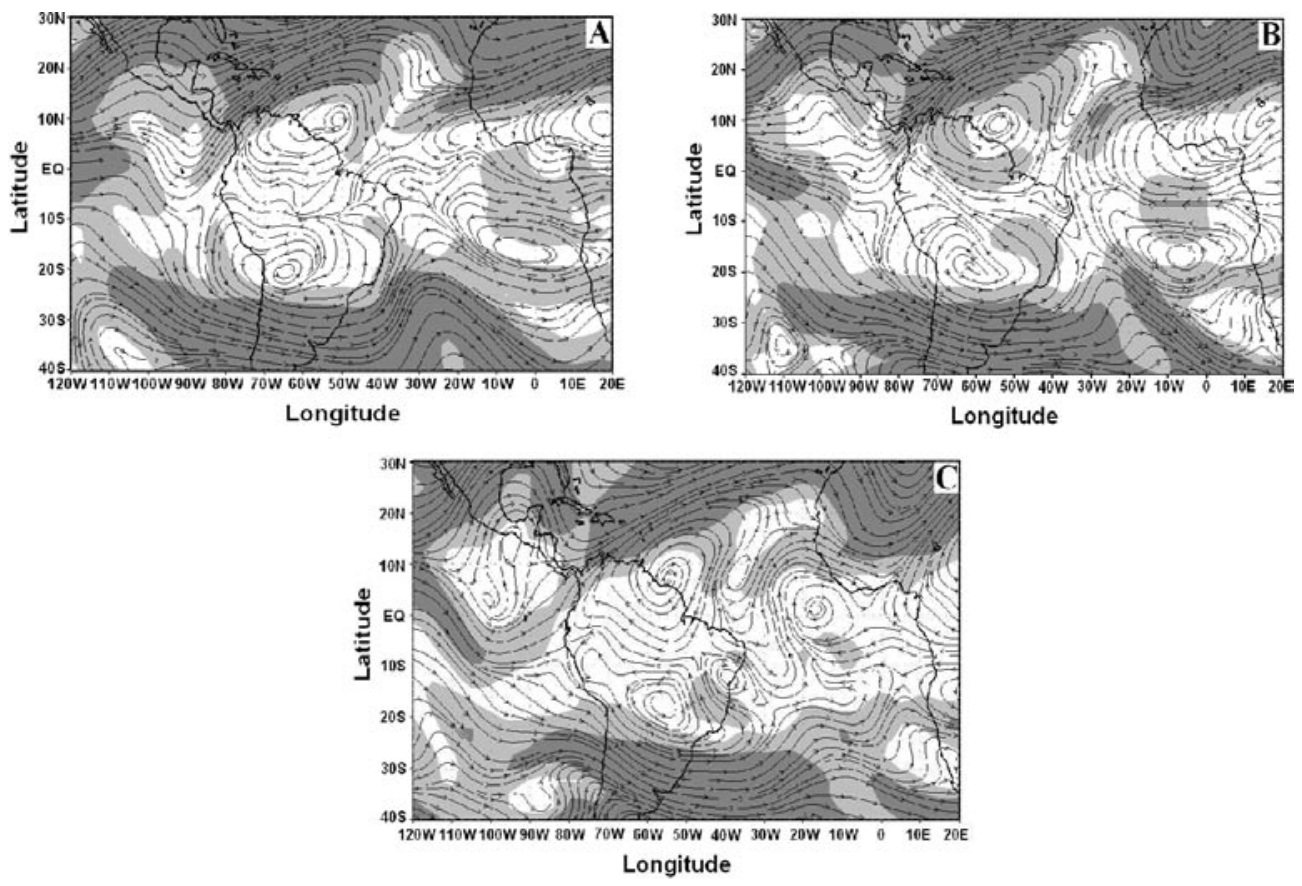

Figura 4 - Linhas de corrente e intensidade do vento no nível de 250hPa às 12:00 UTC do dia: (a) 27, (b) 28 e (c) 29 de março de 1985 . As áreas com tonalidade cinza claro (cinza escuro) correspondem a intensidades acima de $10 \mathrm{~m} / \mathrm{s}(20 \mathrm{~m} / \mathrm{s})$. (Fonte dos dados: NCEP/NCAR).

O campo da vorticidade relativa para as 12:00 UTC mostra vorticidade negativa (ciclônica) nos níveis de $850 \mathrm{hPa}$ (Figura 5a) e 500hPa (não mostrado), e vorticidade ciclônica intensa no nível de $250 \mathrm{hPa}$ (Figura 5b), na área ocupada pelo VCAN (Figura 4c). É possível notar ainda na Figura 5b, o núcleo intenso de vorticidade ciclônica associada ao cavado cuja amplificação parece ter contribuído para a formação do VCAN sobre o Nordeste.

O campo do movimento vertical no nível de $850 \mathrm{hPa}$ para o mesmo horário (Figura 5c) mostra um núcleo intenso de movimentos ascendentes sobre o Nordeste, o que favorece os processos de convecção.
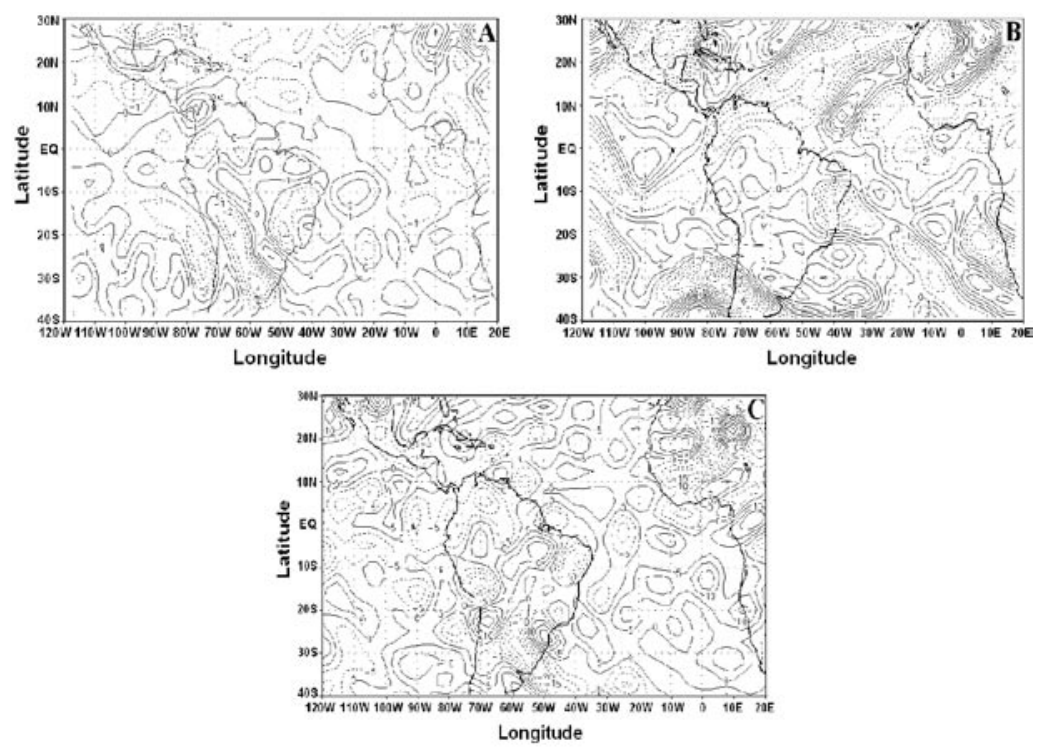

Figura 5 - Análise para as 12:00 UTC do dia 29 de março de 1985 da componente vertical da vorticidade relativa em 850hPa (a) e 250hPa (b), e movimento vertical em $850 \mathrm{hPa}$ (c). O intervalo de análise é de $1,0 \times 10^{-5} \mathrm{~s}^{-1} \mathrm{em} \mathrm{(a,b)} \mathrm{e} \mathrm{5,0} \mathrm{x} 10^{-2} \mathrm{~Pa} \mathrm{~s}^{-1}$ em (c). As linhas contínuas (pontilhadas) correspondem a valores positivos (negativos). (Fonte dos dados: NCEP/NCAR). 
Devido a maior atividade convectiva observada nos campos de radar no período da tarde, são mostrados os campos da divergência horizontal do fluxo de umidade em $925 \mathrm{hPa}$ para as 12:00 UTC e também para as 18:00 UTC. É observada convergência sobre grande parte do Nordeste no dia 27 (Figura 6a), embora a área de Petrolina esteja numa situação de convergência/divergência fraca as 18:00 UTC (Figura 6b). No dia 28, fraca convergência do fluxo de umidade observada pela manhã (Figura 6c) foi substituída por forte divergência do fluxo de umidade sobre a região (Figura 6d). Será visto mais adiante que esse fato deve ter sido o principal responsável pelo pequeno número de ecos observados (não mostrados) na tarde desse dia, que apresentou extensa cobertura de nuvens no período da manhã (Figura 3b). No dia 29, foi observada forte convergência do fluxo de umidade sobre grande parte do Nordeste às 12:00 UTC (Figura 6e) e convergência fraca às 18:00 UTC (Figura 6f). A atividade convectiva foi intensa neste dia, inclusive no período da manhã conforme ilustrado pela Figura 3c.
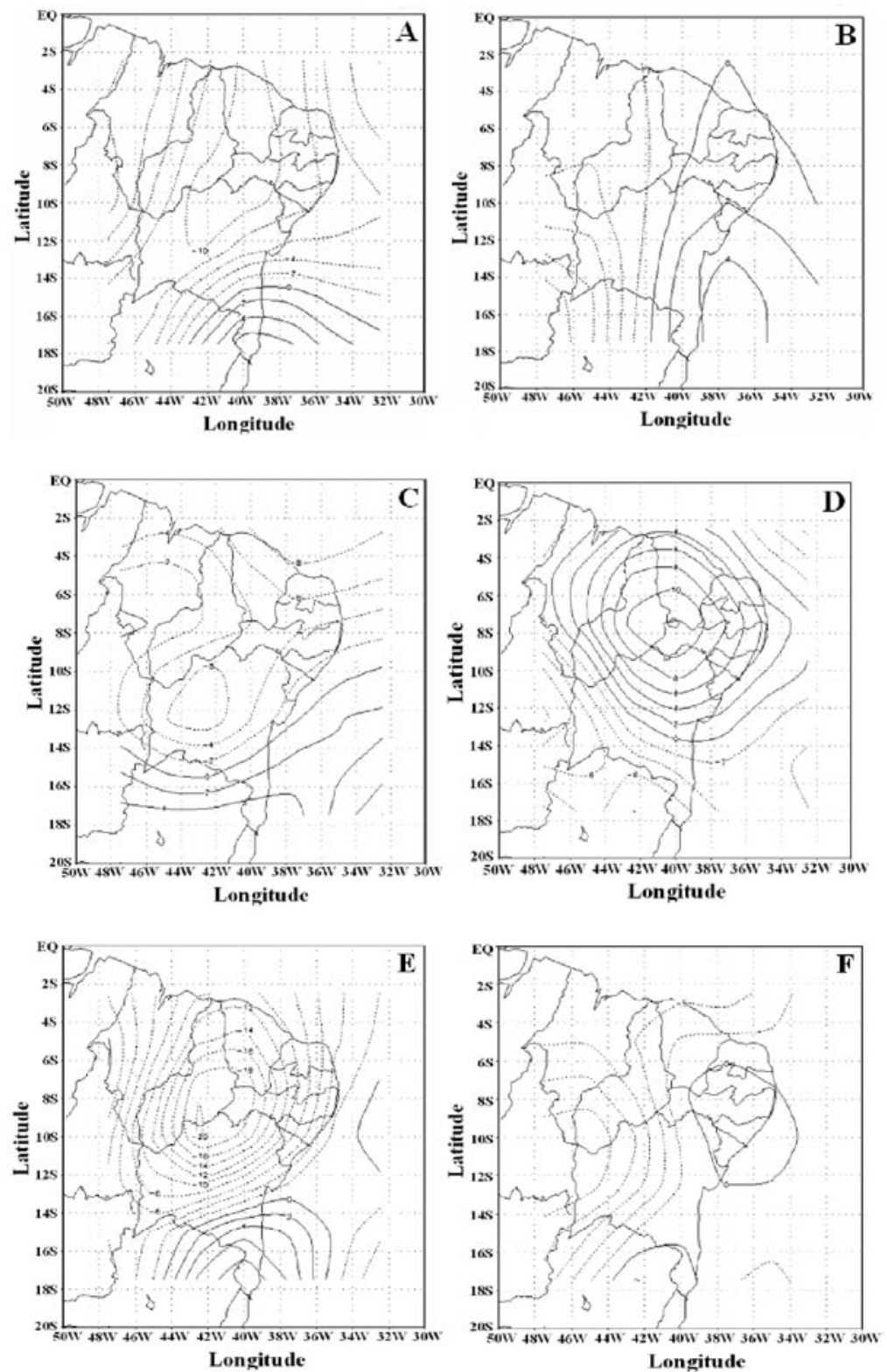

Figura 6 - Divergência horizontal do fluxo de umidade no nível de 925hPa sobre o Nordeste do Brasil, para as 12:00 e 18:00 UTC do dia: (a) e

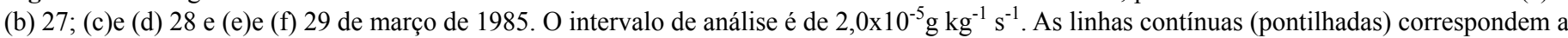
valores positivos (negativos). (Fonte dos dados: NCEP/NCAR). 


\subsection{Características em Mesoescala}

A análise em mesoescala tem como base sondagens diárias de ar superior realizadas no período da manhã em Petrolina e imagens do radar meteorológico banda-C operado naquela cidade, sob a forma de seções horizontais (PPIs) e seções verticais ao longo de determinado azimute (RHIs), estas últimas disponíveis apenas para o dia 29. Estas informações são comparadas às características de grande escala discutidas anteriormente.

\subsubsection{Análise da estabilidade e do vento em altitude}

A presença de instabilidade condicional/convectiva é essencial para formação de células convectivas. Para avaliar o grau de estabilidade da atmosfera foram analisados perfis verticais (Figuras 7a, 7c e 7e) das temperaturas potencial (q), potencial equivalente (qe) e potencial equivalente de saturação (qes) para os três dias analisados, e obtidos valores da CAPE e CINE de uma parcela de ar da superfície (Tabela 2). No entanto, a instabilidade da parcela não é suficiente para caracterizar o ambiente convectivo. Também foi analisado o cisalhamento vertical do vento por meio de hodógrafas e perfis verticais das componentes zonal e meridional do vento.

Tabela 2 - Valores do CAPE e CINE de uma parcela de ar da superfície no período de estudo (em J kg-1) e condições esperadas segundo a classificação de Bluestein (1993).

\begin{tabular}{|c|c|c|c|}
\hline & \multicolumn{3}{|c|}{ DIA } \\
\hline $\begin{array}{c}\text { DF. } \\
\text { ESIABILDADE }\end{array}$ & $27 / 03 / 85$ & $28 / 03 / 85$ & $29 / 03 / 85$ \\
\hline $\begin{array}{c}\text { CAPE } \\
\text { condição esperada }\end{array}$ & $\begin{array}{c}1830 \\
\text { convecção moderada }\end{array}$ & $\begin{array}{c}2380 \\
\text { convecção moderada }\end{array}$ & $\begin{array}{c}1865 \\
\text { convecção moderada }\end{array}$ \\
\hline $\begin{array}{c}\text { CINE } \\
\text { condição esperada }\end{array}$ & $\begin{array}{l}-60 \\
\text { Existe alguma inibiçâo } \\
\text { à convecção que pode } \\
\text { ser vencida por um } \\
\text { lcvantamcnto forçado. }\end{array}$ & $\begin{array}{c}0 \\
\text { Tempestades se formam } \\
\text { espontaneamente e não } \\
\text { costumam ser severas. }\end{array}$ & $\begin{array}{c}-30 \\
\text { Existe alguma inibição à } \\
\text { convecção que pode ser } \\
\text { vencida por um } \\
\text { levantamento forçado. }\end{array}$ \\
\hline
\end{tabular}

No dia 27, o nível de 700 hPa marca a base da camada de inversão térmica mais intensa na qual há uma acentuada redução na umidade atmosférica, o que caracteriza uma inversão de subsidência (Figura 7a). Esse tipo de inversão térmica é típico do período seco na região, época em que o anticiclone subtropical do Atlântico Sul domina a área de Petrolina. O valor constante de q entre a superfície e o nível de $900 \mathrm{hPa}$ evidencia uma camada de mistura profunda neste dia. $\mathrm{O}$ valor do CINE é baixo, -60 $\mathrm{J} \mathrm{kg}^{-1}$, enquanto que o valor da CAPE, $1830 \mathrm{~J} \mathrm{~kg}^{-1}$, indica a possibilidade de ocorrência de convecção moderada caso a inibição convectiva seja rompida, o que foi realmente observado.

No dia 28 , os perfis de qe e qes mostram que a atmosfera esteve mais úmida em toda a baixa e média troposfera, dado que as curvas estão mais próximas do que no dia 27. A curva de qe apresentou valores mais altos entre $700 \mathrm{hPa}$ e $500 \mathrm{hPa}$ no dia 28. Uma camada rasa mais úmida próxima à superfície marca a base de uma camada de inversão que se estende até o nível de $900 \mathrm{hPa}$ (Figura 7c), menos evidente que no dia anterior.

O CAPE é um parâmetro que depende das condições em superfície e da estrutura vertical da atmosfera. No entanto, o alto valor encontrado de $2380 \mathrm{Jkg}^{-1}$, reflete a influência substancial do alto teor de vapor na camada de mistura. Aumento na temperatura da superfície implica no aumento de vapor de água nesta camada. Conseqüentemente, o aumento de ambas as variáveis leva ao aumento da temperatura potencial equivalente. Vários estudos mostram que a CAPE é fortemente correlacionada com a temperatura potencial equivalente na superfície (Machado e Laurent, 2000). Apesar disso, o número de ecos observados foi muito pequeno.

Os perfis verticais das temperaturas potenciais para o dia 29 , mostram condições muito favoráveis à convecção, que foi intensa em toda a área de cobertura do radar neste dia. A comparação entre os perfis das temperaturas potenciais mostra que neste dia a atmosfera também esteve bem misturada, entre a superfície e o nível de $900 \mathrm{hPa}$, o que é um fator importante para promover transferência de calor e umidade (Figura 7c). Os perfis de qe e qes, muito próximos, ilustram um elevado teor de umidade entre os níveis de $930 \mathrm{hPa}$ e $760 \mathrm{hPa}$, este último caracterizando a base de uma inversão de subsidência. Os valores de qe decrescem com o aumento da altura em toda a camada abaixo de $550 \mathrm{hPa}$, evidenciando a presença de instabilidade convectiva. $\mathrm{O}$ valor da CAPE foi de $1865 \mathrm{~J} \mathrm{~kg}^{-1}$, o que indica a possibilidade de convecção moderada, enquanto que foi observada atividade convectiva intensa neste dia (CINE igual a $-30 \mathrm{~J} \mathrm{~kg}^{-1}$ ).

Os perfis verticais das componentes zonal (U) e meridional do vento (V) (Figuras 7b, 7d e 7f) mostram a predominância de ventos de sudoeste na alta troposfera nos três dias. No dia 27 o escoamento é de sudoeste em toda a troposfera acima de $700 \mathrm{hPa}$, e no dia 28 entre $700 \mathrm{hPa}$ e $400 \mathrm{hPa}$ e também acima de $150 \mathrm{hPa}$. No dia 29 o escoamento é de sudoeste e sulsudoeste na maior parte da alta troposfera.

No nível da superfície, o dia 27 apresenta escoamento de leste que gira acentuadamente com a altura mudando para sudeste, sul e finalmente sudoeste em $900 \mathrm{hPa}$. No dia 28 , o vento é de norte em superfície e do terceiro quadrante em quase todo o restante da sondagem. No dia 29 o escoamento entre a superfície e $900 \mathrm{hPa}$ é visivelmente de norte (U zero e $\mathrm{V}$ negativo), mudando para leste entre a baixa e a média troposfera e, acima do nível de $500 \mathrm{hPa}$, o escoamento é do terceiro quadrante até próximo de $100 \mathrm{hPa}$.

Em termos de variação do vento ao longo da vertical, o giro do vetor vento com a altura nestes dias ultrapassou $90^{\circ}$, 

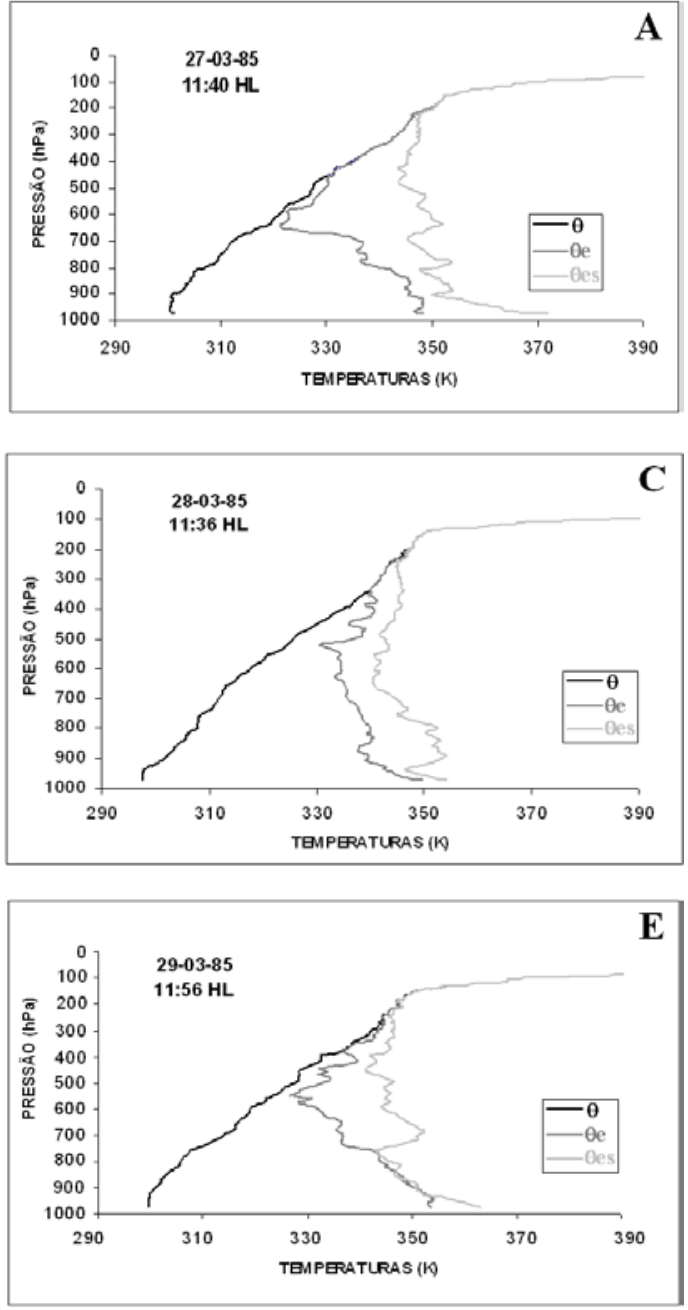
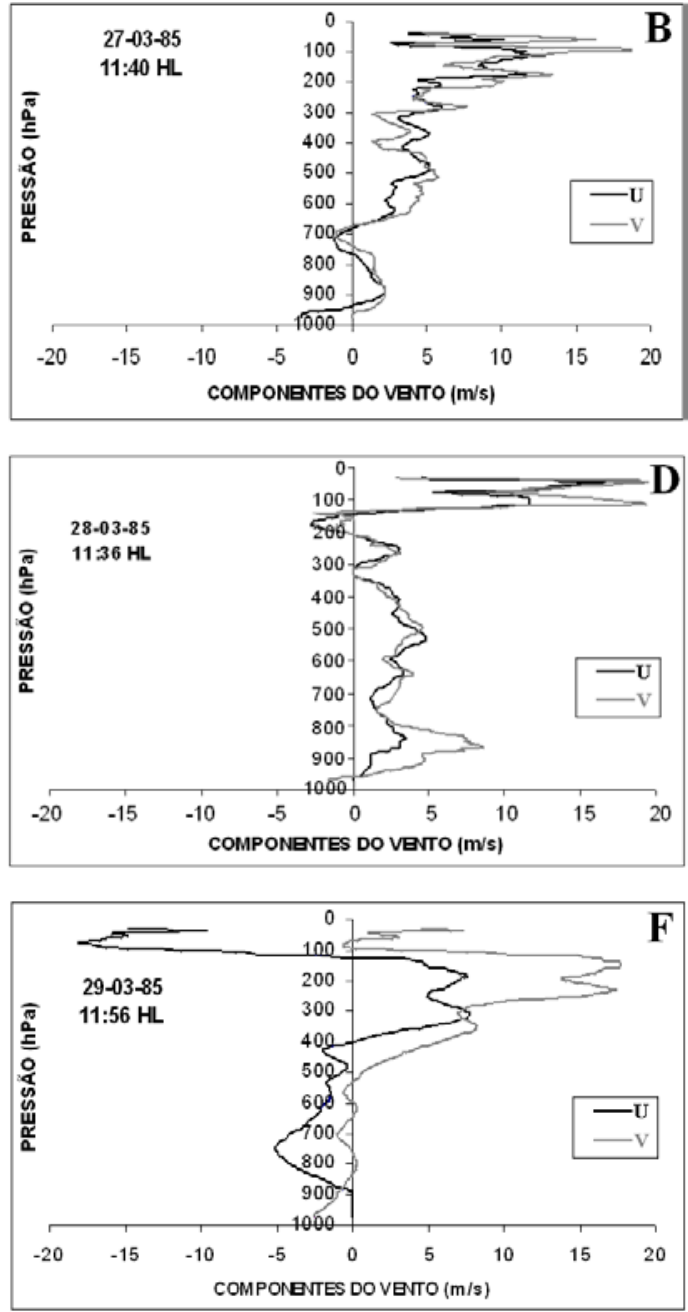

Figura 7 - Perfis verticais da temperatura potencial (q), temperatura potencial equivalente (qe) e temperatura potencial equivalente de saturação (qes) $(\mathrm{a}, \mathrm{c}, \mathrm{e})$, e das componentes zonal (u) e meridional (v) do vento (b,d,f) obtidos de sondagens de ar superior realizadas em Petrolina no dia: (a,b) 27, (c,d) 28 e (e,f) 29 de março de 1985. Valores positivos (negativos) de u indicam componente de oeste (leste). Valores positivos (negativos) de v indicam componente de sul (norte). Os horários das sondagens estão inseridos nos gráficos. Note que HL $=\mathrm{UTC}-3$ horas (Fonte dos dados: IAE/CTA).

quando ventos de leste ou norte em superfície contrastam com ventos de sul-sudoeste em níveis acima da superfície. As hodógrafas para estas sondagens (não mostradas) ilustram um padrão de baixo cisalhamento (menos de $8 \mathrm{~ms}^{-1}$ nos primeiros $5 \mathrm{~km}$ ), e o vetor cisalhamento (vetor tangente à curva da hodógrafa), apresentou valores de $4 \times 10-3 \mathrm{~ms}^{-1}, 5 \times 10^{-3}$ $\mathrm{ms}^{-1}$ e $2 \times 10^{-3} \mathrm{~ms}^{-1}$, respectivamente, para os dias $27,28 \mathrm{e}$ 29. Este é um caso em que o vento apresentou mudanças de direção significativas, mas o vetor cisalhamento não possui giro significativo com a altura. Embora este último fator possa estar associado à tempestades severas (Weisman e Klemp, 1986), tempestades moduladas pelo cisalhamento do vento tipicamente ocorrem em ambientes com ventos atingindo pelo menos 15 $\mathrm{ms}^{-1}$ na metade inferior da atmosfera.

\subsubsection{Análise dos ecos de radar Caso 1) 27 de março}

O conjunto de PPIs mostra ausência quase total de ecos nos quadrantes SE e SW, com exceção de uma área da Chapada Diamantina no quadrante SW. A área preferencial de formação e desenvolvimento dos ecos está situada entre os raios de 100 e $200 \mathrm{~km}$ no quadrante NW e entre os raios de 150 e $250 \mathrm{~km}$ no quadrante NE. Há nos quadrantes NW e NE, em todos os PPIs, ecos dispersos, ecos agrupados sem organização aparente e ecos linearmente organizados. Também é observada fusão de ecos. Tais características são ilustradas na seqüência de PPIs da Figura 8. No primeiro PPI do dia, obtido às 13:13 HL (Figura 8a), há uma FE no quadrante N/NE que também pode ser identificada 

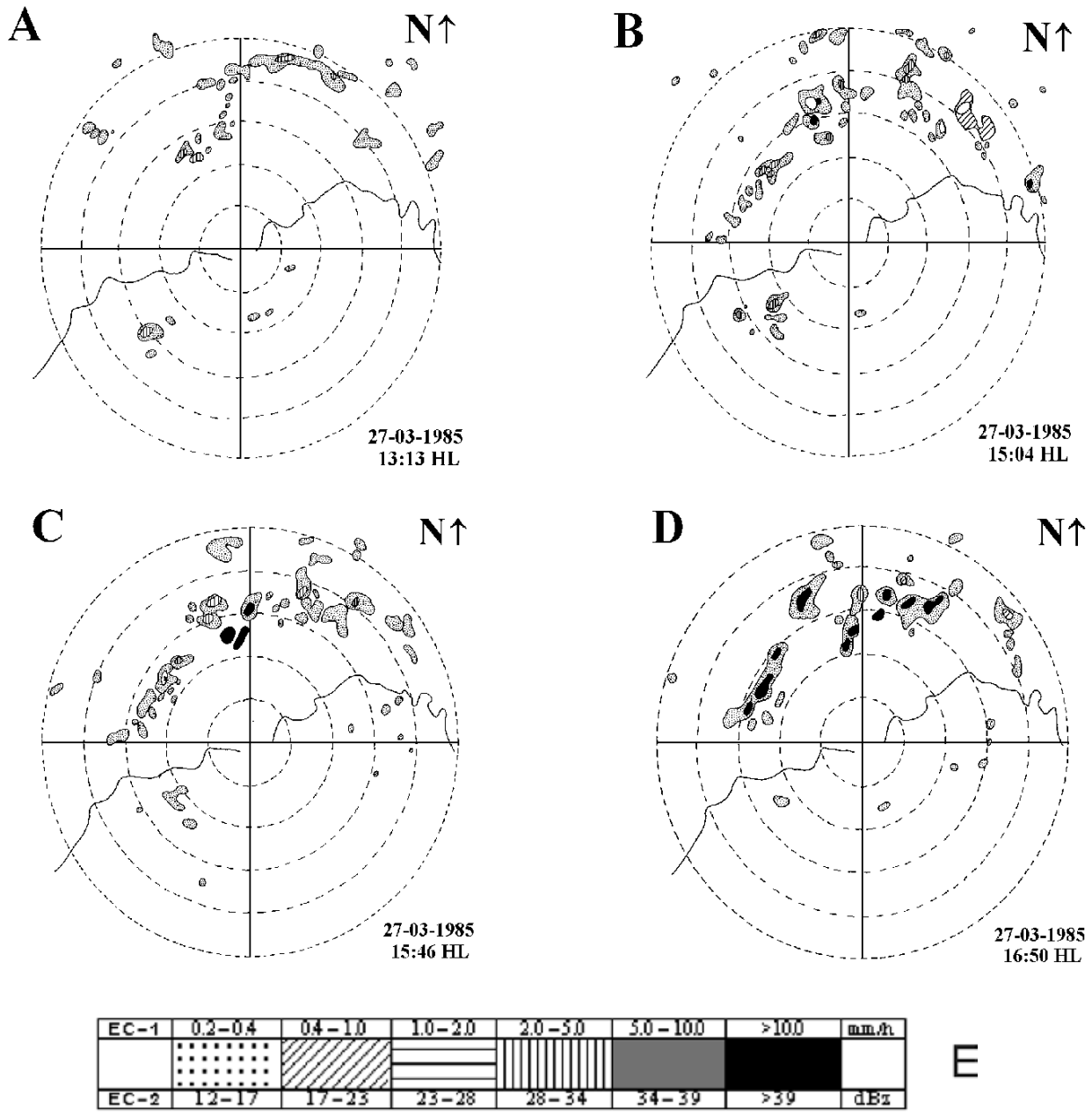

Figura 8 - PPIs do radar meteorológico banda-C de Petrolina-PE obtidos às: (a) 13:13 HL, (b) 15:04 HL, (c) 15:46 HL e (d) 16:50 HL do dia 27 de março de 1985, e (e) convenção utilizada para a taxa de precipitação em mm/h (EC-1) e refletividade em dBz (EC-2). Os círculos concêntricos ao local do radar são espaçados de $50 \mathrm{~km}$. A linha sinuosa situada nos quadrantes nordeste e sudoeste é o curso do Rio São Francisco. A seta no canto superior direito dos PPIs indica o norte geográfico. Note que HL=UTC - 3 horas. (Fonte dos dados: IAE/CTA).

nos PPIs das 13:26 HL, 13:35 HL e 13:50 HL (não mostrados). Após o PPI das 13:50 HL esta FE perde a forma linear. Ecos linearmente organizados na área mais elevada do quadrante NW no PPI das 15:04 HL (Figura 8b) se fundem parcialmente conforme ilustra o PPI das 15:46 HL (Figura 8c). A fusão se completa após esse horário, enquanto que toda a linha se intensifica, atingindo seu máximo no último PPI do dia, às 16:50 HL (Figura 8d). Os PPIs mostram esse sistema sempre com a mesma orientação (SW-NE), se formando e desenvolvendo na mesma área, já que não há deslocamento aparente do mesmo. Dois outros ecos intensos, um situado ao norte do radar e outro no quadrante NW, se fundem e assumem organização linear na direção norte-sul. De maneira geral, é evidente a intensificação dos ecos, particularmente entre as 15:46 e 16:50 HL (Figura $8 \mathrm{c}, \mathrm{d})$. O valor da CAPE, $1830 \mathrm{~J} \mathrm{~kg}^{-1}$, indica a possibilidade de ocorrência de convecção fraca a moderada, o que realmente ocorreu. Fatores dinâmicos de grande escala não foram determinantes para a precipitação observada neste dia, já que a convergência/divergência do fluxo de umidade era fraca às 15:00 HL (Figura 6b).

\section{Caso 2) 28 de março}

Apesar da CAPE ser elevada $\left(2380 \mathrm{~J} \mathrm{~kg}^{-1}\right)$ e da imagem de satélite mostrar atividade convectiva pela manhã (Figura $3 b$ ), foi observado um pequeno número de ecos dispersos sobre áreas elevadas no período da tarde, sugerindo a importância da associação entre o relevo complexo e o aquecimento diurno na formação dos mesmos. O reduzido número de ecos esteve associado à forte divergência horizontal do fluxo de umidade, no horário das 15:00 HL (Figura 6d). Não foram registradas LE e FE neste dia. 


\section{Caso 3) 29 de março}

No período da manhã, já é possível observar a formação e intensificação de uma LE no quadrante SW a partir do PPI das 10:08HL (não mostrado), em uma área marcada por relevo acentuado, com elevações superiores a 1000m. Esta LE é uma das mais importantes dentre as várias que podem ser observadas nos PPIs deste dia, devido a sua formação e evolução ter começado no período da manhã. Esta LE experimenta grande aumento em extensão e núcleos intensos no período da tarde, constituindo uma FE. Ela apresenta orientação SW-NE no PPI das 13:12 HL (Figura 9a), se estendendo entre os raios de $100 \mathrm{e}$ $200 \mathrm{~km}$, aproximadamente. No RHI obtido às 13:08 HL ao longo do azimute de $227^{\circ}$ (Figura 9b), é possível observar sua grande extensão vertical. Novas células formadas nas extremidades sul e oeste da FE provocam mudança de orientação (SW-NE para
N-S), aumento de extensão e aparente deslocamento, como pode ser visto por comparação com o PPI das 14:17 HL (Figura 9c). O RHI obtido às 14:19 $\mathrm{HL}$ ao longo do azimute de $227^{\circ}$ (Figura 9d) mostra, até o raio de $150 \mathrm{~km}$, a estrutura estratiforme característica da chuva associada a células convectivas profundas em estágio de dissipação. Apesar da presença de núcleos intensos, a FE começa a se fragmentar depois desse horário, como pode ser visto na Figura 10. Essa FE de grande extensão e forte intensidade foi observada entre o PPI das 13:12 HL (Figura 9a) e o das 15:19 HL (Figura 10b), apesar de sua máxima intensidade ocorrer às 13:56 HL (não mostrado). Várias LE podem ser vistas nos PPIs da Figura 9, principalmente no quadrante SE, que é o de menor complexidade orográfica.

Muitas LE e FE foram observadas nesse dia, conforme ilustra a seqüência de PPIs da Figura 10:

No quadrante NE, uma LE de orientação NW-SE,
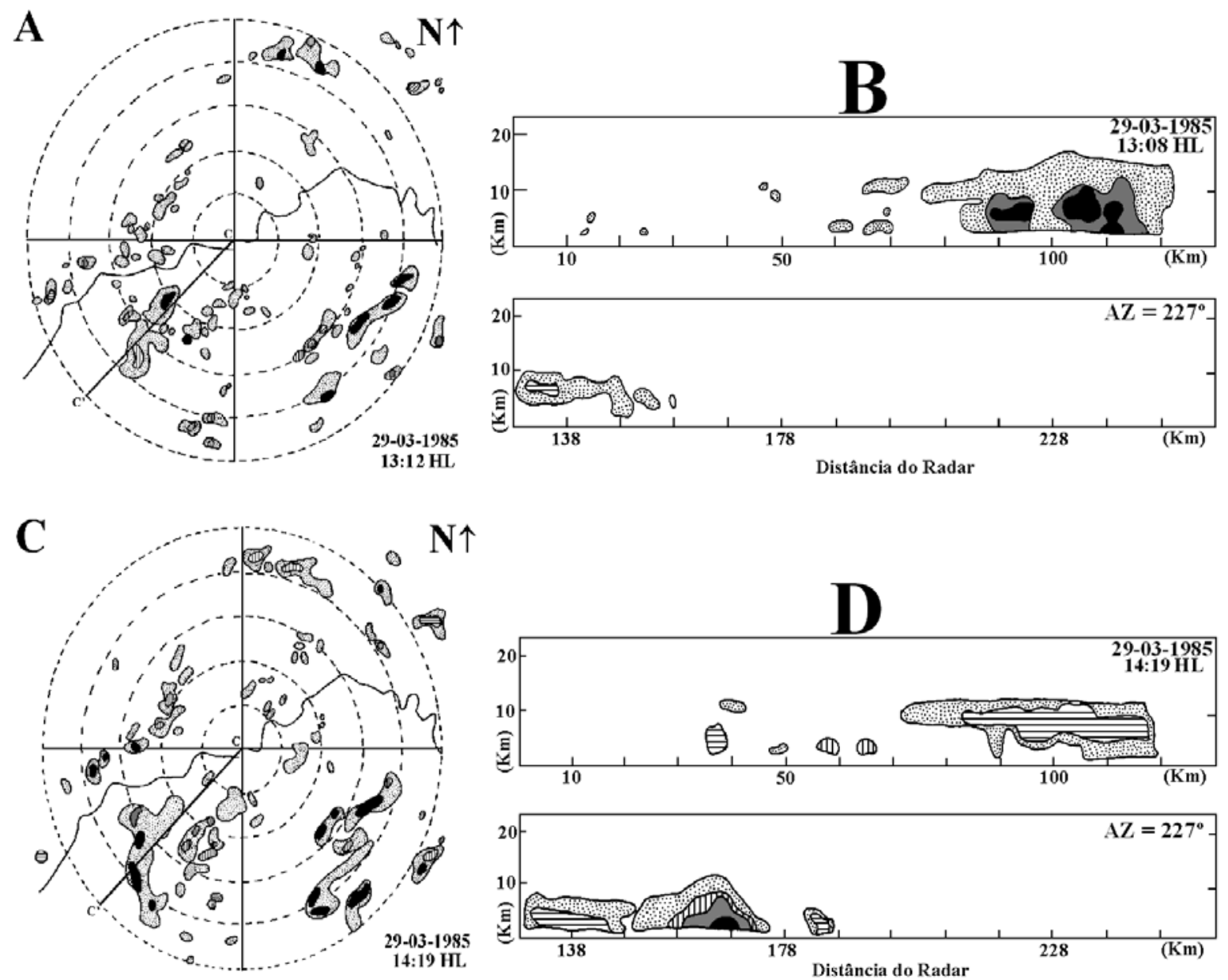

Figura 9 - PPIs do radar meteorológico banda-C de Petrolina-PE obtidos no dia 29 de março de 1985 às 13:12 HL (a) e 14:17 HL (b), e RHIs obtidos às 13:08 HL (c) e 14:19 HL (d), ao longo do azimute de $227^{\circ}$ (linha CC' em (a) e (b)). A simbologia utilizada é igual a da Figura 8. Note que $\mathrm{HL}=\mathrm{UTC}-3$ horas. (Fonte dos dados: IAE/CTA). 
situada em área de relevo elevado (500 a 1000m de altitude) entre os raios de 200 e $250 \mathrm{~km}$, tem desenvolvimento entre as 12:50 HL e 14:30 HL (PPIs não mostrados). Uma segunda LE de mesma orientação, situada inicialmente entre os raios de 200 e $250 \mathrm{~km}$, também passa por forte intensificação, se estendendo entre os raios de 150 e $250 \mathrm{~km}$; sua evolução pode ser acompanhada a partir do PPI das 15:35 HL (não mostrado) até o das 16:55 HL (Figura 10e). A presença de novas células sugere o deslocamento da LE no sentido NE-SW, conforme ilustram as Figuras 10(c)-(e).

Ecos agrupados no quadrante $\mathrm{NW}$, numa área de relevo acentuado com 500 a $1000 \mathrm{~m}$ de altitude, entre os raios de 100 e $150 \mathrm{~km}$, dão origem a uma LE em área próxima a da FE ilustrada na Figura 8d e apresentando a mesma orientação.
Essa LE, que é vista inicialmente no PPI das 14:17 HL (Figura 9c), também passa por forte evolução, constituindo uma FE que atinge inclusive o quadrante $\mathrm{SW}$, conforme ilustram os PPIs das 15:19 HL (Figura 10b) e 15:49 HL (Figura 10c). Uma segunda LE, de orientação N-S, situada próximo ao azimute de $360^{\circ}$ entre os raios de 150 e $250 \mathrm{~km}$, é notada entre os PPIs das 15:04 HL (não mostrado) e 15:49 HL (Figura 10c). Esta também é uma área elevada, com altitudes entre 500 e $1000 \mathrm{~m}$.

A localização dos ecos linearmente organizados nos quadrantes NE, NWeSW parece estardiretamenterelacionadacomo relevo das áreas sobre as quais são observados, já que suas altitudes variam de 500 a $1000 \mathrm{~m}$, superando os $1000 \mathrm{~m}$ no quadrante $\mathrm{SW}$.

$\mathrm{O}$ valor da CAPE, $1865 \mathrm{~J} \mathrm{~kg}^{-1}$, é condizente com a atividade convectiva observada neste dia. O CINE calculado,
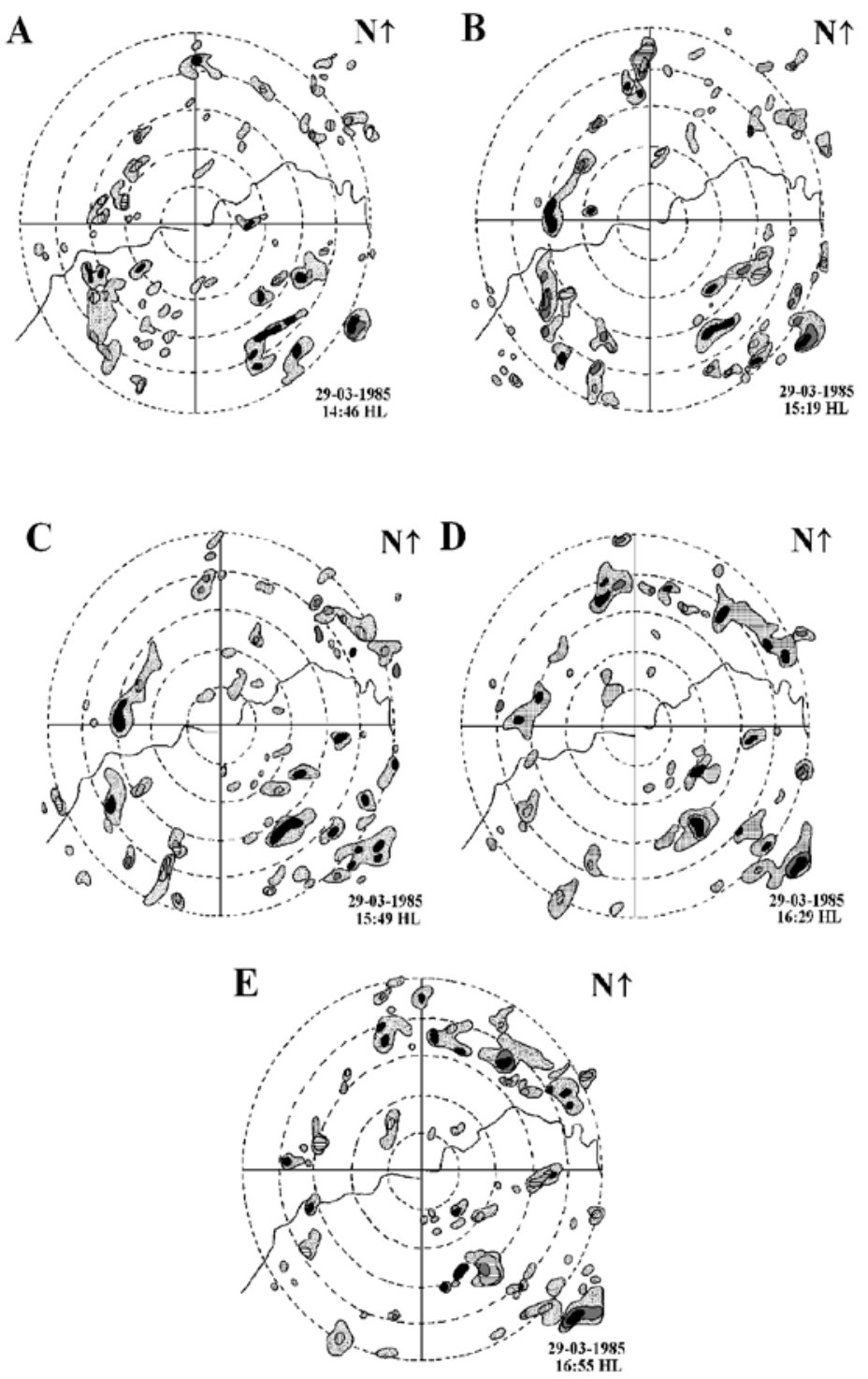

Figura 10 - Seqüência de PPIs do radar meteorológico banda-C de Petrolina-PE obtidos no dia 29 de março de 1985 às: (a) 14:46 HL, (b) 15:19 HL, (c) 15:49 HL, (d) 16:29 HL, e (e) 16:55 HL. A simbologia utilizada é igual a da Figura 8. Note que HL=UTC - 3 horas. (Fonte dos dados: IAE/CTA). 
$-30 \mathrm{~J} \mathrm{~kg}^{-1}$, é um valor baixo para inibir a convecção das parcelas de ar. Combinada a estes fatores, convergência horizontal do fluxo de umidade, forte às 12:00 UTC (Figura 6e) e fraca às 18:00 UTC (Figura 6f), contribui para a grande quantidade e intensidade dos ecos observados.

\section{CONCLUSÕES}

No cenário de grande escala, a presença de um cavado de ar superior (austral) sobre o Nordeste no dia 27 favorece a presença de nebulosidade convectiva sobre a região. A amplificação de um cavado na circulação de oeste sobre o Atlântico Norte tropical provoca mudanças na circulação em altos níveis sobre o Nordeste contribuindo, no dia 29, para a formação de um vórtice ciclônico de altos níveis (VCAN) centrado sobre a área oceânica a leste da região. Nesse cenário, a presença de convergência do fluxo de umidade próxima à superfície é um fator decisivo para a intensa atividade convectiva do dia 27 e, em particular, para o elevado número de núcleos intensos observados no dia 29. Em contrapartida, a convecção é inibida por forte divergência de umidade às 15:00 HL do dia 28, contrastando com a nebulosidade convectiva observada na imagem de satélite obtida na manhã desse dia.

A estrutura termodinâmica avaliada através de sondagens diárias de ar superior realizadas em Petrolina evidencia mudanças significativas no período de estudo: um grande aumento no teor de umidade na camada limite planetária e o enfraquecimento da inversão de subsidência típica da região.

No cenário de mesoescala, as análises mostram atividade convectiva intensa no período da tarde, o que evidencia a importância do aquecimento diurno na formação e intensificação de ecos. Outro fato marcante é o papel importante da orografia na formação e organização dos ecos. Os resultados sugerem que, além do aquecimento diurno e suprimento de umidade da grande escala, é um fator primordial para o desenvolvimento das linhas de ecos (LE). De maneira geral, as LE e FE observadas estão em áreas de terrenos elevados e são compostas de núcleos convectivos intensos e áreas de precipitação estratiforme, numa estrutura característica das linhas de instabilidade. As LE e FE observadas no dia 27 parecem estacionárias, enquanto que a formação de novas células sugere o aparente deslocamento e tempo de vida mais longo das LE e FE registradas no dia 29.

Os valores obtidos para o CAPE foram condizentes com a atividade convectiva observada nos dias 27 e 29 . No dia 28, o CAPE teve o valor mais elevado (2380 $\mathrm{J} \mathrm{kg}^{-1}$ ), o que contrasta com a pouca atividade de chuva desse dia. Esse resultado mostra que valores altos da CAPE representam uma condição necessária, mas não suficiente para o desenvolvimento de atividade convectiva intensa na região. Foram observados valores baixos do CINE nos três dias.

\section{REFERÊNCIAS BIBLIOGRÁFICAS}

ARAÚJO, H.A. Padrões de Ecos de Radar Meteorológico no Semi-Árido Brasileiro e Condições Atmosféricas Associadas. Dissertação de Mestrado em Meteorologia. Campina Grande: Universidade Federal da Paraíba. Paraíba. 130 pp. 1996.

BARBOSA, T.F.; CORREIA, M.F. Sistemas convectivos intensos no semi-árido brasileiro: o controle da grande escala. Revista Brasileira de Meteorologia, V. 20, p. 395410, 2005.

BLUESTEIN, H.B., 1993: Synoptic-Dynamic Meteorology. Vol I and II. Oxford University Press, New York, 431pp and 594pp.

BOLTON, D. The Computation of Equivalent Potential Temperature. Monthly Weather Review, 108. 1046-1980 pp. 1980.

COHEN, J.C.P.; DIAS, M.A. F. S.; NOBRE, C.A.; Environmental Conditions Associated with Amazonian Squall Lines: A Case Study. Monthly Weather Review, p. 3163-3174, Vol 123, 1995.

CORREIA M.F. Diagnóstico Via Radar dos Sistemas Precipitantes do Semi-Árido Brasileiro: O Evento de 1985. Dissertação de Mestrado em Meteorologia. São Paulo: Universidade de São Paulo. 88 pp., 1989.

DINIZ, M.C.S.; CORREIA, M.F.; SILVA ARAGÃO, M.R. Convecção profunda no submédio do Rio São Francisco: uma avaliação das condições atmosféricas na área do aeroporto de Petrolina-PE. Revista Brasileira de Meteorologia, V. 19, p. 273-286, 2004.

DOMINGUES, M. O.; MENDES JR, O.; CHAN, C. S.; SÁ, L. D. A.; MANZI, A. O. Análise das condições atmosféricas durante a 2a. Campanha do Experimento Interdisciplinar do Pantanal Sul Mato-Grossense. Revista Brasileira de Meteorologia, São Paulo, v.19, n.1, p.73-88, 2004.

GARSTANG, M.; MASSIE Jr, H. L.; HALVERSON, J.; GRECO, S.; SCALA, J. Amazon Coastal Squall Lines. Part I: Structure and Kinematics. Monthly Weather Review, V. 122, p. 608-622, 1994.

GRECO, S.; SCALA, J.; HALVERSON, J.; MASSIE Jr, H, L.; TAO, W, K.; GARSTANG, M.; Amazon Coastal Squall Lines. Part II: Heat and Moisture Transports. Monthly Weather Review, p. 623-635, Vol 122, 1994.

HASTENRATH, S., 1984: Interannual variability and annual cycle: mechanisms of circulation and climate in the tropical Atlantic. Monthly Weather Review, v. 112, 1097-1107.

HASTENRATH, S.; Heller L., 1977: Dynamics of climatic hazards in north-east Brazil. The Quarterly Journal of The Royal Meteorological Society, 110, 411-425.

KOUSKY, V.E. Frontal influences on Northeast Brazil. Monthly 
Weather Review, v. 107, p. 1140-1153, 1979.

KOUSKY, V.E.; GAN, M.A. Upper Tropospheric Cyclonic Vortices in the Tropical South Atlantic. Tellus, v.33, p. 538-551, 1981.

KOUSKY, V. E.; KAYANO M. T., 1994: Principal modes of outgoing longwave radiation and $250-\mathrm{mb}$ circulation for the South American sector. Journal of Climate, 7, 1131-1143.

MACHADO, L.A.T.;LAURENT, H. Características dinâmicas e termodinâmica da convecção observadas na amazônia durante o AMC/LBA. In: XI Congresso Brasileiro de Meteorologia, Rio de Janeiro, 2000.

MENEZES, W. F. Tempestades Severas - Um modelo para latitudes subtropicais; Tese de doutorado; 1997.

MOURA, A. D.; SHUKLA, J.1981: On the dynamics of droughts in northeast Brazil: Observations, theory and numerical experiments with a general circulation model. Journal of the Atmospheric Science, 38, 2653-2675.

SILVA ARAGÃO, M.R.; CORREIA, M.F.; ARAÚJO, H.A. Characteristics of C-Band meteorological radar echoes at Petrolina, Northeast Brazil. International Journal of Climatology, V. 20, p. 279-298, 2000.

SILVA ARAGÃO, M.R.; DAMIÃO MENDES, M.C., CAVALCANTI, I.F.A., CORREIA, M.F. Observational study of a rainy January day in the Northeast Brazil semi-arid region: synoptic and mesoscale characteristics. Quarterly Journal of the Royal Meteorological Society, V. 133, p. 1127-1141, 2007. DOI: 10.1002/qj.81

SILVA DIAS, M.A.F. Sistemas de mesoescala e previsão de tempo a curto prazo. Revista Brasileira de Meteorologia; 1987; Vol. 2, 133-150.

WEISMAN M. L., KLEMP J.B. Characteristics of isolated convective storms. In Mesoscale Meteorology and Forecasting (P.Ray, ed.), p.331-358. American Meteorological Soviety, Boston. 1986.

ZAWADZKI, I. I.; RO, C.U. Correlation Between Maximum Rate of Precipitation and Mesoscale parameters. Journal of Applied Meteorology, v. 17, 1978. 